\title{
PENERAPAN METODE BIOFILIK PADA TRANSFORMASI GUBAHAN MASSA RUANG INTERAKTIF BERBASIS EKOLOGIS SEBAGAI BANGUNAN BEYOND ECOLOGY DI KEMANGGISAN
}

\author{
William Japardy¹), Martin Halim²) \\ 1)Program Studi S1 Arsitektur, Fakultas Teknik, Universitas Tarumanagara, japardywilliam@gmail.com \\ 2) Program Studi S1 Arsitektur, Fakultas Teknik, Universitas Tarumanagara, martinhalim90@gmail.com
}

Masuk: 04-07-2021, revisi: 14-08-2021, diterima untuk diterbitkan: 23-10-2021

\begin{abstract}
Abstrak
Beyond Ecology berarti melampaui dari hanya sekedar hubungan timbal balik antar mahkluk hidup dengan lingkungan sekitarnya. Krisis ekologi mulai disuarakan sejak tahun 1960-an, dimana sebagian besar orang mulai memikirkan kembali relasi mereka terhadap alam ketika tindakan manusia mulai mengancam keseimbangan alam dan mengasingkan manusia dengan kehidupan selain dirinya. Dengan dunia yang mengalami percepatan ini dikhawatirkan dengan keberlangsungan suatu ekosistem. Banyak kerusakan ekosistem yang disebabkan oleh tingkah manusia seperti pemburuan hewan, pembuangan limbah, dan kebakaran hutan yang mencapai puncaknya pada tahun 2019 yang disebabkan oleh sikap ketidakpedulian manusia. Menurut Bintarto, Hal ini sering terjadi di daerah perkotaan besar dengan kepadatan yang tinggi menimbulkan sifat acuh tak acuh manusia dengan lingkungannya. Hadirnya ruang interaktif yang didasarkan pada desain yang ekologis menjadi jawaban dari permasalahan yang ada. Adapun Jakarta yang merupakan kota metropolitan terbesar di Indonesia sehingga menjadi sasaran dalam perancangan kali ini tepatnya di daerah Kemanggisan. Melihat dari karakter kawasannya didominasi oleh fasilitas Pendidikan formal ,area perkantoran, dan berada di sekitar area perbelanjaan. Metode Stack dari Bejamin Bratton serta biofilik desain merupakan acuan pada perancangan ini sebagai upaya untuk menumbuhkan rasa empati dan peduli masyarakat terhadap lingkungannya. Adapun program yang berupa wadah pendidikan dan perkantoran sebagai bentuk pendukung aktivitas warga sekitar yang didominasi oleh karyawan dan pelajar. Area terbuka dan stage menjadi strategi terciptanya kawasan yang tidak hanya berfokus pada wadah dan pembelajaran masyarakat melainkan sebagai kawasan untuk berekreasi yang tidak lupa dari ekologi itu sendiri.
\end{abstract}

Kata kunci: Biofilik Arsitektur; Krisis Sosial; Tempat Rekreasi ; Wadah Aktivitas

\begin{abstract}
Beyond Ecology means beyond just the reciprocal relationship between living things and the surrounding environment. The ecological crisis began to be voiced in the 1960s, where most people began to rethink their relationship to nature when human actions began to threaten the balance of nature and alienate humans from life other than themselves. With the world experiencing this acceleration, there are concerns about the sustainability of an ecosystem. Much of the damage to ecosystems caused by human behavior such as hunting for animals, dumping waste, and forest fires that reached their peak in 2019 is caused by human indifference. According to Bintarto, this often happens in large urban areas with high density, causing humans to be indifferent to their environment. The presence of an interactive space based on an ecological design is the answer to the existing problems. As for Jakarta, which is the largest metropolitan city in Indonesia, it is the target in this design, precisely in the Kemanggisan area. Judging from the character of the area, it is dominated by formal education facilities, office areas, and is located around the shopping area. The Stack method from Benjamin Bratton and the biophilic design are the references in this design as an effort to foster a sense of empathy and care for the community towards the environment. The program is in the form of educational institutions and offices as a form of supporting the activities of residents, which are dominated by employees and students. Open areas and stages are a strategy to create an area that does not only focus on community forums and learning but as an area for recreation that does not forget about ecology itself.
\end{abstract}

Keywords: Activity Spaces; Architectural Biophilic; Recreation; Social Crisis 


\section{PENDAHULUAN}

\section{Latar Belakang}

Jakarta Merupakan kota metropolitan terbesar di Indonesia. Dengan Kepadatan penduduk yang cukup tinggi, tidak mengherankan jika banyak permasalahan ekologi yang harus di hadapi kota Jakarta. Hal ini disebabkan oleh kegiatan industry polutif, pembuangan sampah sembarangan, penggunaan, asap kendaraan bermotor dalam skala besar, dan lainnya yang dapat menimbulkan kerusakan Ekologi. Kesadaran masyarakat lah yang menjadi akar dari permasalahan yang dihadapi ini. Bersumber pada kompas.com, dari hasil survey 8 sungai di Jakarta $80 \%$ pencemaran diakibatkan limbah rumah tangga dan sisanya dari limbah pabrik (Rastika, 2016). Selain itu, bersumber pada kompas.com menyatakan bahwa, Kendaraan Bermotor menyumbangkan 60\% polusi di Jakarta (Kurniawan, 2020).

Perbincangan mengenai kehancuran pada bumi menjadi landasan krisis ekologi. Berbagai penelitian oleh para ahli membuktikan bahwa eksistensi lingkungan hidup kelestariannya mulai terancam secara signifikan. Direktur Eksekutif Program Lingkungan PBB menyatakan:

"Dunia kita berada di tepi kehancuran lantaran ulah manusia. Di seluruh planet, sumber-sumber alam dijarah kelewat batas. Disebutkan juga, pada setiap detik, diperkirakan sekitar 200 ton karbon dioksida dilepas ke atmosfir dan 750 ton top soil musnah. Sementara itu, diperkirakan sekitar 47.000 hektar hutan dibabat, 16.000 hektar tanah digunduli, dan antara 100 hingga 300 spesies mati setiap hari. Pada saat yang sama, secara absolut jumlah penduduk meningkat 1 milyar orang per dekade. Ini menambah beban bumi yang sudah rentan." (Heriyanto, 2005).

Maraknya krisis ekologi sudah dimulai sejak tahun 1960-an, dimana sebagian besar orang mulai memikirkan kembali relasi mereka terhadap alam ketika tindakan manusia mulai mengancam keseimbangan alam dan mengasingkan manusia dengan kehidupan selain dirinya. Hingga saat ini, orang-orang berlomba lomba untuk menciptakan teknologi yang dapat menembus batas ruang dan waktu. Dengan dunia yang mengalami percepatan ini dikhawatirkan dapat mengancam keberlangsungan suatu ekosistem.

Oleh karena itu, untuk menghadapi berbagai permasalah kota Jakarta perlu adanya ruang interaktif yang dapat mengedukasi masyarakat mengenai pentingnya kesadaran masyarakat terhadap lingkungan. Diharapkan, dalam proyek perancangan ini dapat menumbuhkan rasa peduli dan empati manusia terhadap lingkungannya. Dimulai dari kebiasaan masyarakat itu sendiri dengan berbekal lingkungan sekitar terutama bagi masyarakat perkotaan.

\section{Rumusan Permasalahan}

a. Bagaiman cara mengubah pandangan dan pola pikir manusia terhadap lingkungannya ?

b. Bagaimana peran arsitektur dalam menghadapi permasalahan perkotaan yang bersumber pada kesadaran masyarakat?

\section{Tujuan}

a. Mewadahi masyarakat sekitar untuk melaksanakan aktivitas sehari hari berdampingan dengan lingkungannya.

b. Memberikan fungsi komersil di tengah daerah perkotaan yagn padat sebagai area rekreasi

c. Memberikan pembelajaran mengenai ekologi kepada para pengunjung melalui interactive space

d. Menjadi contoh bagi masyarakat mengenai keterkaitan manusia dan lingkungannya.

\section{KAJIAN LITERATUR}




\section{Deep Ecology}

Fritjof Capra dalam artikelnya yang berjudul Deep Ecology: A New Paradigm menyatakan bahwa antroposentris adalah ekologi dangkal (shallow ecology) yang mempunyai cara pandang berbeda dengan ekologi dalam (deep ecology), dengan uraian sebagai berikut:

"Ekologi dangkal (shallow ecology) merupakan antroposentris yang melihat manusia berada di atas atau di luar alam sebagai pusat dari seluruh nlai, dan menganggap alam hanya sebagai suatu instrumen alam. Seorang ilmuwan bernama Seyyed Hossein Nasr menyatakan "Manusia modern telah mendesakralisasi alam (Nasr, 2005). Alam telah dipandang sebagai sesuatu yang harus digunakan dan dimanfaatkan semaksimal mungkin. Bukannya seperti seorang wanita yang menikah, dimana laki-laki harus memikul tanggung jawab, begitu juga alam bagi manusia modern telah menjadi seperti seorang pelacur - dimanfaatkan namun tanpa ada arti kewajiban dan tanggung jawab terhadapnya". Ekologi dalam (deep ecology) manyatukan manusia dengan lingkungan alam, dan tidak memisahkan segala sesuatunya dari lingkungan alam. Deep Ecology tidak melihat dunia sebagai suatu kumpulan kelompok elemen tetapi sebagai suatu jaringan fenomena yang saling terhubung dan saling ketergantungan secara fundamental. Deep ecology mengakui nilai-nilai instrinsik dari semua makluk hidup dan memandang manusia hanya sebagai salah satu bagian khusus dalam jaringan kehidupan (the web of life). Paradigma ekologi baru ini (deep ecology) menyiratkan sebagai suatu paradigma ekologi baru saat ini. Kerangka etika yang terkait dengan paradigma lama tidak lagi memadai untuk menangani beberapa masalah etika utama saat ini, yang sebagian besar menyebabkan ancaman terhadap bentukbentuk kehidupan selain manusia." (Satmaidi, Jurnal Penelitian Hukum, 2015)

Deep ecology yang oleh Capra disebut sebagai paradigma ekologi baru merupakan gagasan Arne Naess seorang filsuf Norwegia pada tahun 1973. Menurut Naess untuk mengatasi kondisi ekologis (The Emergency of Ecologists) dapat dibedakan dua gerakan penyelamatan lingkungan yaitu shallow ecological movement (SEM) dan deep ecological movement (DEM). DEM perlu dipahami dalam latar belakang kritiknya terhadap antroposentrisme atau lebih luas dikenal sebagai shallow ecological movement (SEM) yang dapat dikemukakan sebagai berikut: "SEM berasumsi krisis lingkungan merupakan persoalan teknis, yang tidak membutuhkan perubahan dalam kesadaran manusia. DEM justru sebaliknya, melihat permasalahan lingkungan dalam suatu perspektif relasional yang lebih luas dan holistik. DEM lebih berusaha untuk melihat akar permasalahan kerusakan dan pencemaran lingkungan secara lebih komprehensif dan holistik, untuk kemudian mengatasinya secara lebih mendalam. Aspek sosial dan manusia juga menjadi perhatian utama DEM. Sementara, SEM lebih cenderung mengatasi gejala dari sebuah isu lingkungan dan bukan akar permasalahan. (Satmaidi, Jurnal Penelitian Hukum, 2015)

\section{Beyond Ecology}

Beyond Ecology 'melampaui ecology' adalah sebuah kondisi ekosistem dengan kondisi formasi sosialnya yang mengalami kondisi kecepatan dan percepatan. Pada titik ini, Kecepatan menjadi jantung dunia keseharian dan Ekosistem disekitar kita mengalami 'pemadatan waktu' (time compression) sebagai konsekuensi dari percepatan kehidupan.

Parameter dalam Arsitektur menuju Beyond Ecology (Sutanto, 2021) :

- ENERGY and EMISSION adalah kemampuan untuk menerapkan zero C02 emission dalam bangunan dan meminimalisir efek dalam material dan konstruksi.

- ADAPTATION adalah kemampuan untuk melakukan riset dan desain yang berkaitan dengan dampak, seperti naiknya suhu bumi, naiknya permukaan laut, kekeringan, banjir, kelangkaan pangan, prubahan populasi.

- RESILIENCE adalah kemampuan untuk kelanjutan 'hunian' dan pemulihan cepat setelah kejadian guncangan, bencana alam, gangguan listrik atau iklim

- SUSTAINABLE DIGITAL adalah kænampuan untuk melihat data-data lingkungan sebagai Big Data dalam menentukan taktik dan strategi dalam membangun kualitas 
- NEW TECHNOLOGY adalah kemampuan memanfaatkan teknologi terbaru untuk meningkatan kualitas dan terapan ruang - kontruksi dan program bangunan.

- CONTEXT adalah kemampuan dalam melihat tempat dalam hubungan dengan lingkungan (flora - fauna, biotic - abiotic) dimana sebuah konfigurasi keruangan akan ditempatkan

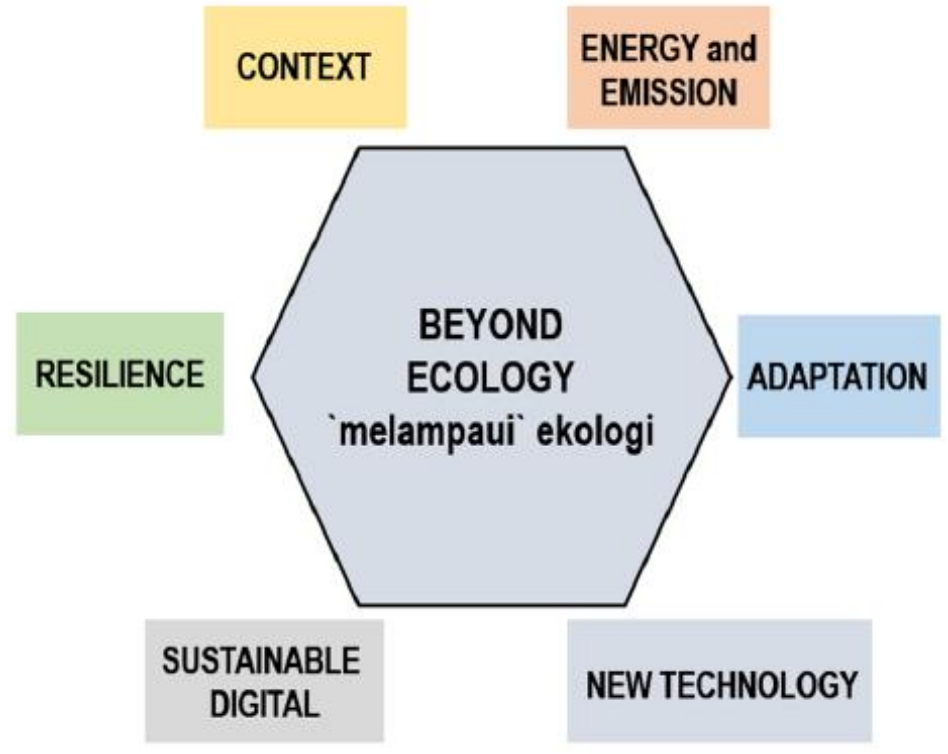

Gambar 1 Beyond Ecology

Sumber : (Sutanto, 2021)

\section{Faktor-Faktor yang Mempengaruhi Perilaku Peduli lingkungan Masyarakat}

Perilaku kepedulian seseorang atau masyarakat terhadap lingkungan dapat di dasari melalui model perilaku ekologi dari Fietkau \& Kessel. Model ini terdiri dari 5 unsur yang berpengaruh baik secara langsung maupun tidak langsung terhadap 122 perilaku peduli lingkungan. (Kollmuss \& Agyeman, 2002)

- Sikap dan nilai

Sikap peduli lingkungan yang teridentifikasi berlandaskan pada nilai-nilai yang diyakini kebenarannya.

- Kemungkinan untuk bertindak secara ekologis

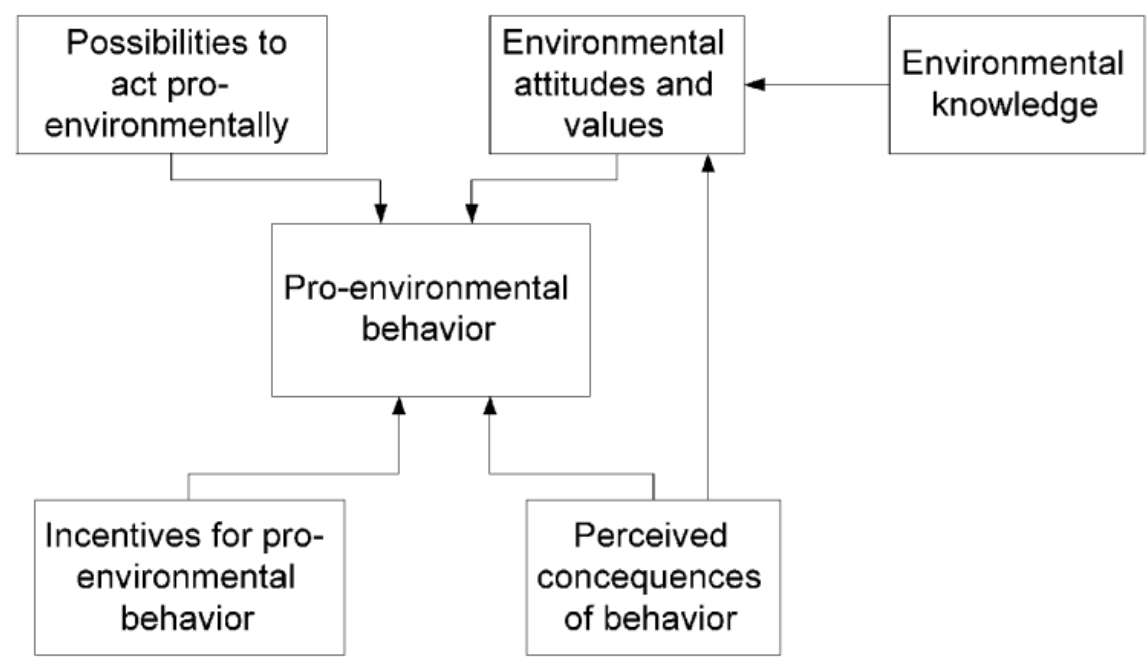

Gambar 2. Model Perilaku Ekologis

Sumber : (Kollmuss \& Agyeman, 2002) 
unsur eksternal, faktor infrastruktur dan ekonomi berperan penting untuk menjadi jembatan atau halangan bagi orang bertindak secara ekologis.

- Insentif perilaku Insentif merupakan faktor penting yang perlu diperhatikan dalam perilaku pro-lingkungan dan dapat membuat masyarakat mencintai lingkungannya. Insentif dapat berupa kesadaran yang muncul dari komponen informasi dan motivasi dari rasa dihargai karena kegiatan yang dilakukan.

- Umpan balik yang dirasakan tentang perilaku ekologis

Umpan balik ini dapat bersifat intrinsik (misalnya dengan pelestarian lingkungan mendapatkan rasa senang atau kepuasan dalam diri karena dapat bermanfaat bagi orang lain.) atau ekstrinsik (misalnya dengan lingkungan yang sehat dan bersih meningkatkan daya tarik kawasan yang dapat berpengaruh pada perekonomian masyarakat sekitar oleh pengunjung yang ramai).

- Pengetahuan

Pengetahuan tidak langsung mempengaruhi tetapi berperan penting sebagai pengubah sikap dan nilai.

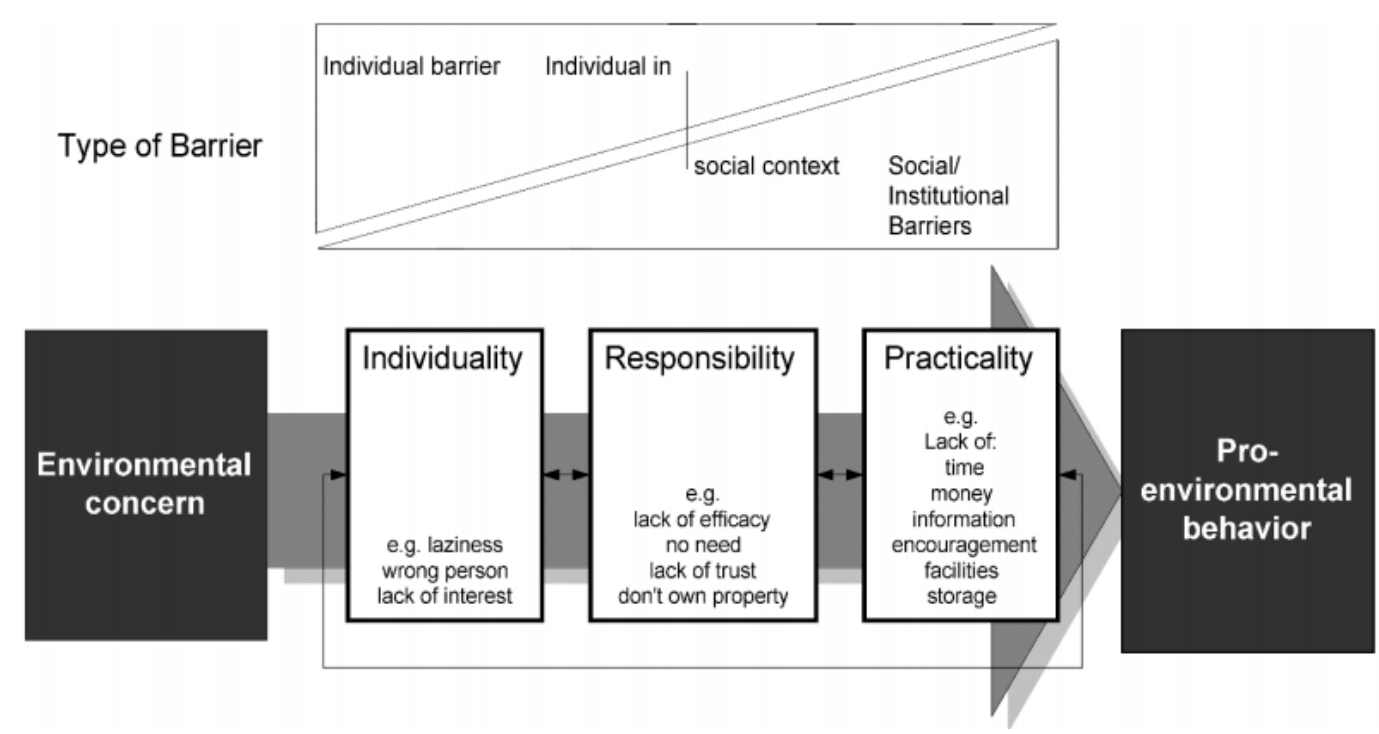

Gambar 3 . Hambatan Terhadap Kepedulian Lingkungan

Sumber : (Kollmuss \& Agyeman, 2002)

Blake mengidentifikasi tiga hambatan untuk bertindak pro-lignkungan : individualitas, tanggung jawab, dan kepraktisan.

- Hambatan individu adalah hambatan yang terletak di dalam diri perseorangan. Dia mengklaim bahwa hambatan ini terutama berpengaruh pada orang yang tidak memiliki kepedulian lingkungan yang kuat. Oleh karena itu, kepedulian terhadap lingkungan sebanding dengan sikap-sikap lain yang saling bertentangan. Namun, dalam pengalaman kami, bahkan kepedulian lingkungan yang kuat dapat terkalahkan oleh keinginan dan kebutuhan yang lebih kuat. Misalnya, kebutuhan para pelajar luar negeri untuk Kembali ke negaranya, mereka setiap tahun mengesampingkan perasaan tanggung jawab kita tentang menjaga perjalanan udara kita seminimal mungkin untuk meminimalkan pemanasan global.

- Hambatan kedua, "tanggung jawab" sangat dekat dengan gagasan psikolog tentang "tempat kendali". Orang-orang yang tidak bertindak pro-lingkungan merasa bahwa mereka tidak dapat mempengaruhi situasi atau tidak harus mengambil tanggung jawab untuk dia. Dia menunjukkan bahwa dalam komunitas tertentu yang dia gambarkan, kurangnya kepercayaan di lembaga sering menghentikan orang untuk bertindak pro-lingkungan karena mereka curiga 
terhadap pemerintah lokal dan nasional, mereka kurang bersedia mengikuti tindakan yang ditentukan.

- Hambatan ketiga, "kepraktisan" dideefinisikan sebagai sosial dan institusional kendala yang mencegah orang dari bertindak pro-lingkungan terlepas dari sikap atau niat mereka. Dia mencantumkan kendala seperti kurangnya waktu, kurangnya uang, dan kurangnya informasi. Meskipun modelnya sangat berguna dalam hal itu menggabungkan faktor eksternal dan internal dan menjelaskan keduanya secara rinci, dia melakukannya tidak memperhitungkan faktor sosial seperti tekanan keluarga dan norma budaya atau SARA (Kollmuss \& Agyeman, 2002).

\section{METODE}

Terkait dengan kondisi pademi saat perancangan, metode yang digunakan berupa analisis kualitatif berupa survey tapak secara online untuk mengetahui kondisi tapak, fasilitas disekitar tapak, pergerakan manusia di daerah Kemanggisan, serta potensi tapak. Selain itu, studi preseden yang diambil dari internet juga menjadi acuan desain. Metode Stack dari Bejamin Bratton yang dipilih sebagai metode perancangan untuk menyatukan hasil analisis dan konsep desain dalam rancangan Ruang Interaktif Berbasis Ekologis ini. Metode desain biofilik arsitektur juga merupakan landasan dalam perancangan desain ruang interaktif ini dalam mendekatkan masyarakat dengan lingkungan.

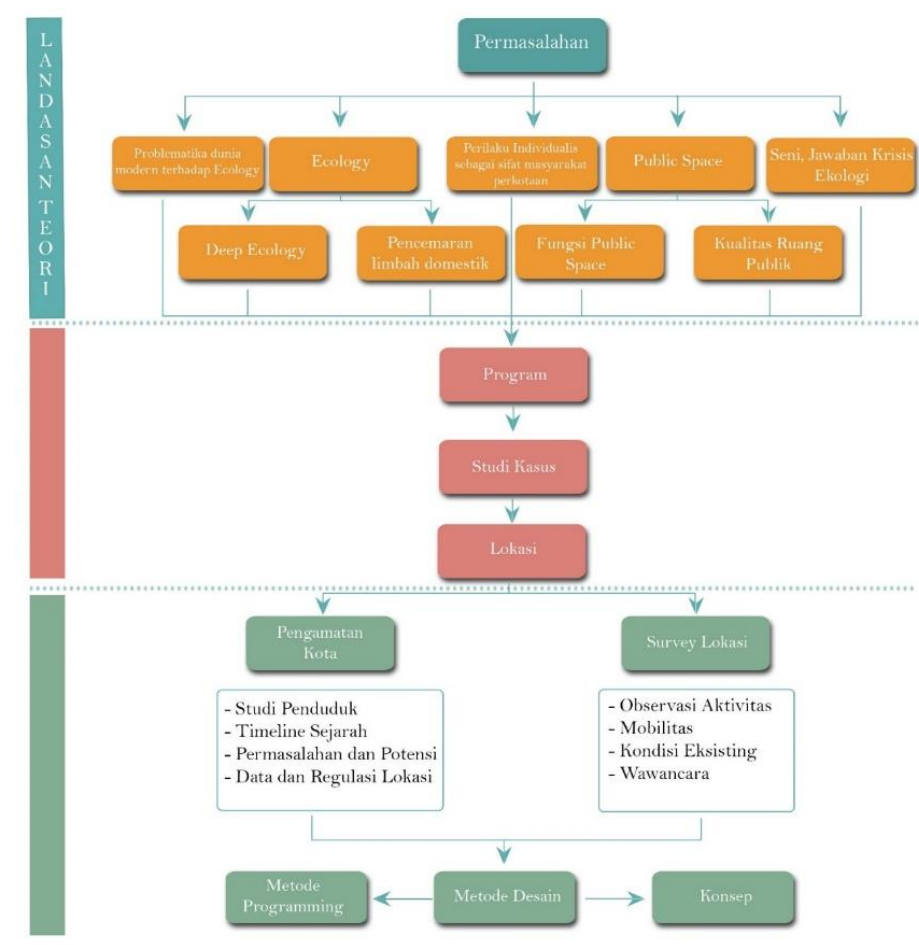

Gambar 4. Tahapan dan Langkah-langkah Proses Studi Sumber : Penulis,2021

Desain Beyond Urban Ecology : Stack yang merupakan metode desain dari Benjamin Bratton (Bratton, 2016) dalam desain arsitektur perkotaan dimana didalamnya terdapat 6 unsur, antara lain :

- User

Aktivitas penghuni / pengguna pada kawasan sebagai dasar dalam menentukan program agar mereka dapat berinteraksi dengan sekitarnya

- Interface

Berupa Teknologi yang digunakan untuk permasalahan yang dihadapi agar mempermudakan bagi penghuni / pengguna. 
- Address

Kriteria tapak terhadap lingkungan sekitar.

- City

Akses tapak terhadap ransportasi umum serta kedekatan tapak terhadap program sekitar.

- Cloud

Konsep yang digunakan berdasarkan isu tapak dan sekitarnya bersama program apa yang akan diambil berdasarkan aktivitas penguna.

- Earth

Kondisi iklim pada tapak serta kondisi topografi yang dibutuhkan terkait fungsi yang diambil.

Adapun Biofilik arsitektur yang menjadi acuan desain, sebagai berikut :

Nature in the Space

1. Hubungan secara visual (Visual connection with nature)

Memberi akses kepada manusia dengan pemandangan alam dan proses alami.

2. Hubungan non visual dengan alam (Non-visual connection with nature)

Koneksi dengan alam yang diberikan melalui indra pendengaran, penciuman, peraba dan perasa yang mengingatkan manusia kepada alam, sistem kehidupan dan proses alami.

3. Stimulus sensor tidak beritme (Non-rhytmic sensory stimuli)

Memberikan rangsangan sensorik alami agar menarik perhatian dengan memberi gerakan tidak terprediksi yang terkadang tidak disadari oleh individu.

4. Variasi perubahan panas \& udara (Thermal and airflow variability)

Adanya variasi dalam perubahan sistem suhu, kelembaban dan gerakan angin di dalam ruangan kepada manusia seakan berada di alam liar.

5. Kehadiran air (Presence of water)

Memberikan unsur air dengan tujuan menambah pengalaman individu dengan melihat, mendengar dan menyentuh elemen air dalam suatu tempat atau ruang.

6. Cahaya dinamis dan menyebar (Dynamic and diffuse lighting)

Pemanfaatan intensitas cahaya dan Memberikan bentuk cahaya secara dinamis dan menyebar secara alami, untuk menciptakan suatu kondisi perubahan waktu yang terjadi di alam.

7. Hubungan dengan sistem alami (Connection with natural system)

Menggunakan material atau elemen alam dengan meminimalkan proses pengolahan untuk mempertahankan bentuk alami serta karakteristik yang sama dengan alam.

\section{Natural analogues}

1. Bentuk dan pola biomorfik (Biomorphic forms and patterns)

Meniru alam melalui pola, bentuk dan tekstur sebagai elemen struktur ataupaun dekoratif pada desain bangunan.

2. Hubungan bahan dengan alam (Material Connection with Nature)

Menggunakan material atau elemen alam dengan meminimalkan proses pengolahan sehingga masih mencerminkan ekologi dan geologi lokal dari alam.

3. Kompleksitas dan keteraturan (Complexity and order)

Informasi sensorik beragam yang menganut hirarki spasial mirip dengan yang ada di alam.

Nature of the space

1. Prospek (Prospect)

Mendesain ruang dengan pandangan tanpa hambatan yang luas, terbuka dan lapang.

2. Tempat perlindungan (Refuge)

Memberikan rasa aman dan terlindungi pada pengguna dari segala sisi.

3. Misteri (Mystery) 
Menciptakan suasana yang menarik agar membuat pengunjung ingin menjelajah lebih dalam lagi.

4. Resiko dan Bahaya (Risk \& Peril)

Pemberian rasa bahaya atau ancaman tetapi memiliki perlindungan yang aman.

Model perilaku ekologis Fietkau \& Kessel menjadi landasan dalam perancangan untuk merubah pola pikir dan cara pendang masyarakat terhadap ekologi, antara lain 4 unsur yang dapat dipenuhi dalam perancangan arsitektur :

- Kemungkinan untuk bertindak secara ekologis unsur eksternal, faktor infrastruktur dan ekonomi berperan penting untuk menjadi jembatan atau halangan bagi orang bertindak secara ekologis.

- Insentif perilaku Insentif merupakan faktor penting yang perlu diperhatikan dalam perilaku pro-lingkungan dan dapat membuat masyarakat mencintai lingkungannya. Insentif dapat berupa kesadaran yang muncul dari komponen informasi dan motivasi dari rasa dihargai karena kegiatan yang dilakukan.

- Umpan balik yang dirasakan tentang perilaku ekologis

Umpan balik ini dapat bersifat intrinsik (misalnya dengan pelestarian lingkungan mendapatkan rasa senang atau kepuasan dalam diri karena dapat bermanfaat bagi orang lain.) atau ekstrinsik (misalnya dengan lingkungan yang sehat dan bersih meningkatkan daya tarik kawasan yang dapat berpengaruh pada perekonomian masyarakat sekitar oleh pengunjung yang ramai).

- Pengetahuan

Pengetahuan tidak langsung mempengaruhi tetapi berperan penting sebagai pengubah sikap dan nilai.

\section{DISKUSI DAN HASIL}

Dari hasil analisis yang didapat dirangkai dalam satu kesatuan menggunakan metode stack dari Bejamin Bratton sebagai berikut :

User

Target pengunjung dari proyek ini berdasarkan penduduk di wilayah sekitar Kemanggisan yang didominasi orang perkantoran, pelajar, serta usia muda dengan rentang umur mayoritas usia produktif dan usia muda.

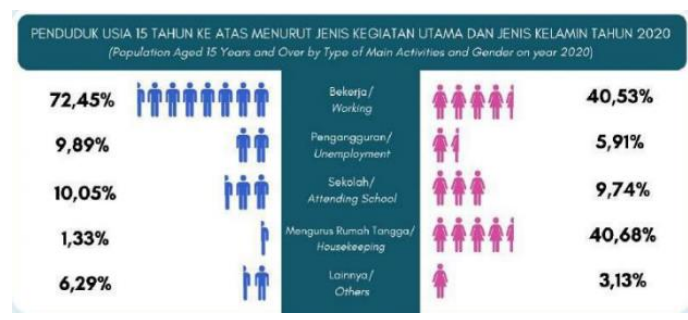

Gambar 6 Kegiatan Utama Penduduk Jakarta Barat

Sumber : jakbarkota.bps.go.id
Jumlah Penduduk Jakarta Barat Kelompok Umur (Jiwa), 2018-2020

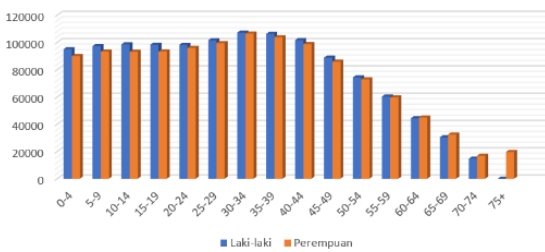

Gambar 6. Jumlah Penduduk Jakarta Barat 20182020

Sumber : jakbarkota.bps.go.id

\section{Interface}

Teknologi dan program yang ditawarkan berupa area self farming dan digital interactive space dengan menggunakan teknologi teknologi proyeksi, sensor gerak, hologram, dan lainnya. 


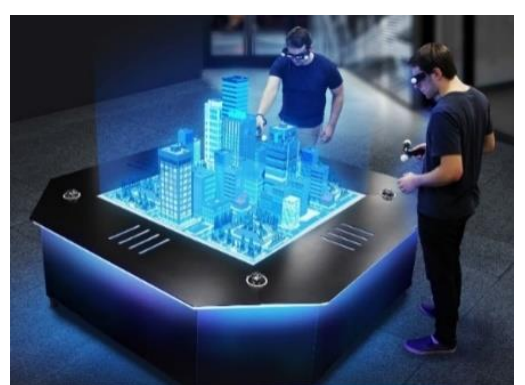

Gambar 8.Human Sensor System Sumber : areacewe.com

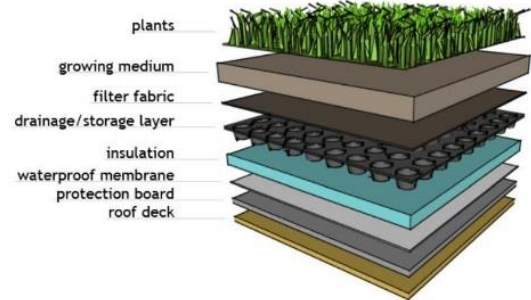

Gambar 8. Roof Garden Sumber : myrooff.com

\section{Address \& City}

Tapak yang dipilih berupa daerah yang memiliki kepadatan tinggi dan cukup strategis. Selain itu, tapak juga harus terletak dekat dengan trasnportasi umum untuk mendukung mobilitas pejalan kaki dan menjadikan kawasan yang walkable.

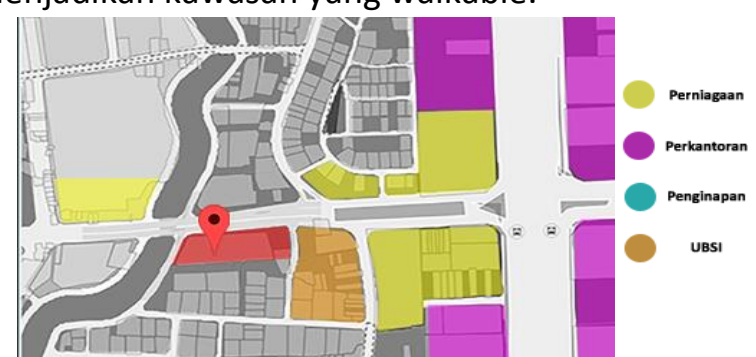

gambar 10 Data Pergerakan Manusia

Sumber : google maps

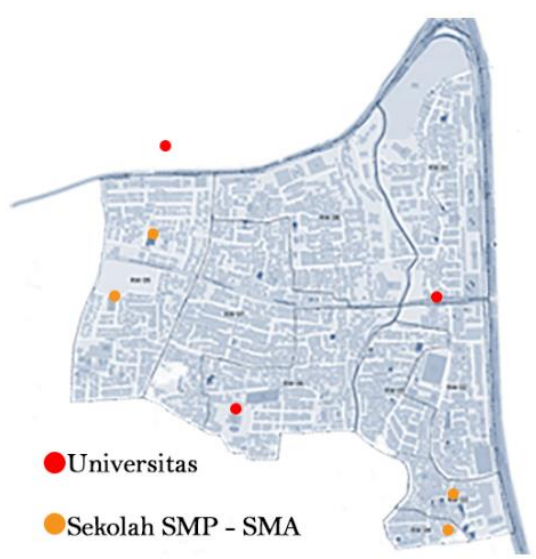

Gambar 11. Data Sarana dan Prasarana Kesenian Sumber : google maps

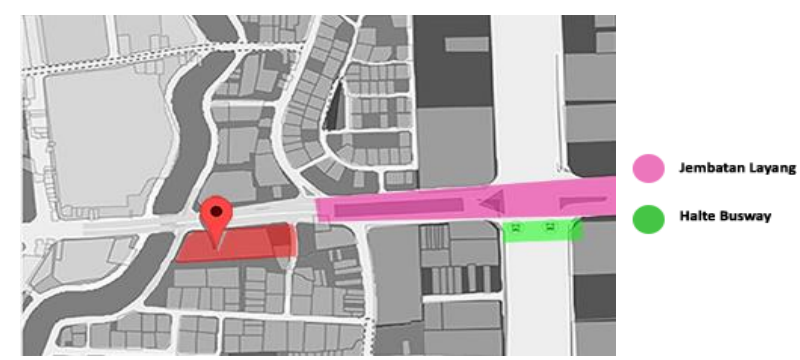

gambar 10 Data Sarana dan Prasarana Transbortasi

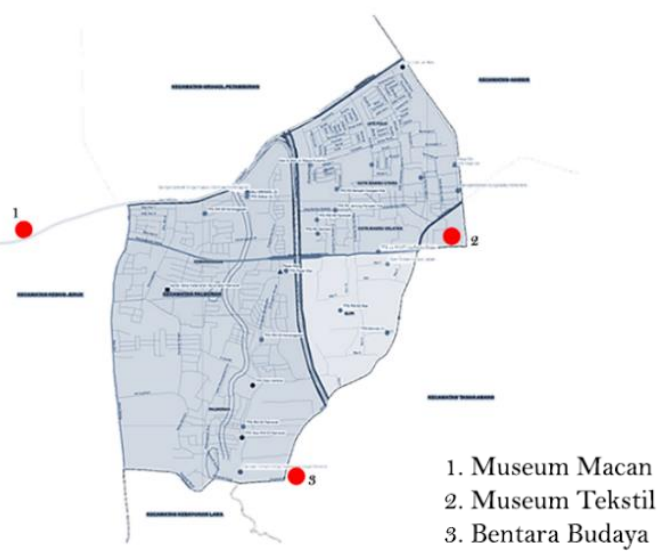

Gambar 12. Data Sarana dan Prasarana Kesenian Sumber : google maps

Analisis Pergerakan Manusia

Dilihat dari bangunan di sekitar tapak masih di mayoritasi oleh daerah perkantoran serta tapak dikelilingi oleh area perniagaan menjadikan program working space serta fungsi rekreasi cocok untuk mendukung fungsi kawasan.

Analisis Sarana dan Prasarana Transportasi

Jalan Kemanggisan Utama yang terletak di bagian utara tapak serta adanya transportasi umum berjarak sekitar 150 meter dari tapak menjadikan bagian utara tapak fokus utama akses masuk kawasan. 
Analisis Sarana Prasarana Pendidikan

Daerah Kemanggisan terdapat berbagai sarana pendidikan SMP dan SMA serta adanya Universitas UBSI (disebelah tapak) dan BINUS sebagai alasan terwujudnya program learning space. Selain itu, daerah Kemanggisan berhimpitan dengan Grogol yang merupakan kawasan pendidikan yang mendukung adanya program learning space.

Analisis Sarana dan Prasarana Kesenian

Dari data yang didapat, tapak memiliki koneksi yang baik dengan beberapa banguan kesenian di sekitar tapak, sehingga program ruang seni interaktif ini dapat menjadi pilihan yang tepat dan program utama untuk mengedukasi masyarakat mengarah ke pemikiran pro-lingkungan.

\section{Earth}

Kondisi tapak Jakarta merupakan daerah dataran rendah dengan tanah datar. Dan iklim di Indonesia merupakan iklim tropis basah sehingga menggunakan prinsip prinsip arsitektur tropis.

\section{Cloud}

Konsep yang digunakan berupa "desain biofilik" yang diambil dari buku Terapin berjudul "14 Pattern of Biophilic Design" (Browning, Ryan, \& Clancy, 2014) yang diterapkan dalam proyek Ruang Interaktif Berbasis Ekologis sebagai berikut :

\section{- Visual Connection With Nature (Hubungan Dengan Alam Secara Visual)}
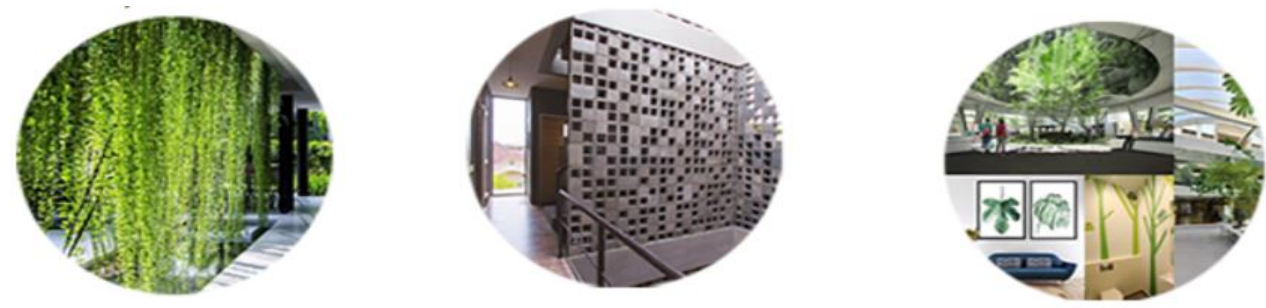

Penerapan terhadap desain bangunan berupa : penggunaan elemen alam dan sebagai bagian dari desain, dinding dan material bangunan transparan, keterhubungan massa bangunan dengan alam Gambar 12.Visual Connection with Nature Sumber : homediarymagazine.com

melalui void, tanaman, dll.

- Non-Rhytmic Sensory Stimuli (Stimulus Sensor Tidak Berirama)

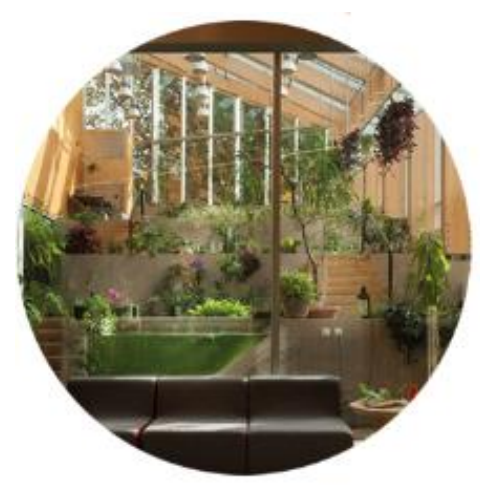

Gambar 13. Non-Rhytmic Sensory Stimuli Sumber : idea.grid.id 
- Penciptaan warna dan suasana interior dengan memanfaatkan tumbuhan dan bentuk bentuk organik

- Dynamic And Diffuse Lighting (Cahaya Dinamis dan Menyebar)

Penerapan terhadap desain berupa penggunaan skylight untuk memasukkan pencahayaan alami.

- Presence Of Water (Kehadiran Air)

Penerapan terhadap desain bangunan berupa penggunaan elemen air untuk memberikan kenyamanan dan ketenangan.

- Prospect (Prospek)

Penerapannya terhadap desain bangunan berupa adanya keterhubungan langsung dengan alam (tidak hanya melalui lukisan atau lainnya) melalui bukaan dan desain eksisting tapak.

- Refuge (Tempat Perlindungan )

Penerapan dalam desain bangunan berupa adanya pembagian zona dan desain semi tertutup untuk menjaga privasi pengguna berdasarkan fungsi masing-masing.

- Mystery (Misteri)

Penerapan dalam desain bangunan membuat penggunjung semakin tertarik untuk menjelajahi kawasan.

- Biomorphic Forms \& Patterns (Bentuk Dan Pola Biomorfik)

Bentuk dan Pola Biomorfik diambil dari elemen alam berupa tumbuhan teratai. Teratai memiliki makna yang akan selalu indah di temat yang kotor.

Diharapkan hasil proyek interactive space ini dapat tampil dan mengedukasi ditengah lingkungan "Shalow Ecology" serta memberikan pencerahan terhadap masyarakat tentang pentingnya peran manusia dalam suatu ekologi.

Adapun faktor faktor pembentuk pro-lingkungan yang diterpakan pada rancangan ini :

- Kemungkinan untuk bertindak secara ekologis

Menyediakan wadah bagi para masyarakat untuk menjalankan aktivitas kehidupan berdampingan dengan lingkungan dengan menarik desain biofilik arsitektur yang dapat mendukung terciptanya keterkaitan antar pengguna dan lingkungan.

- Insentif perilaku

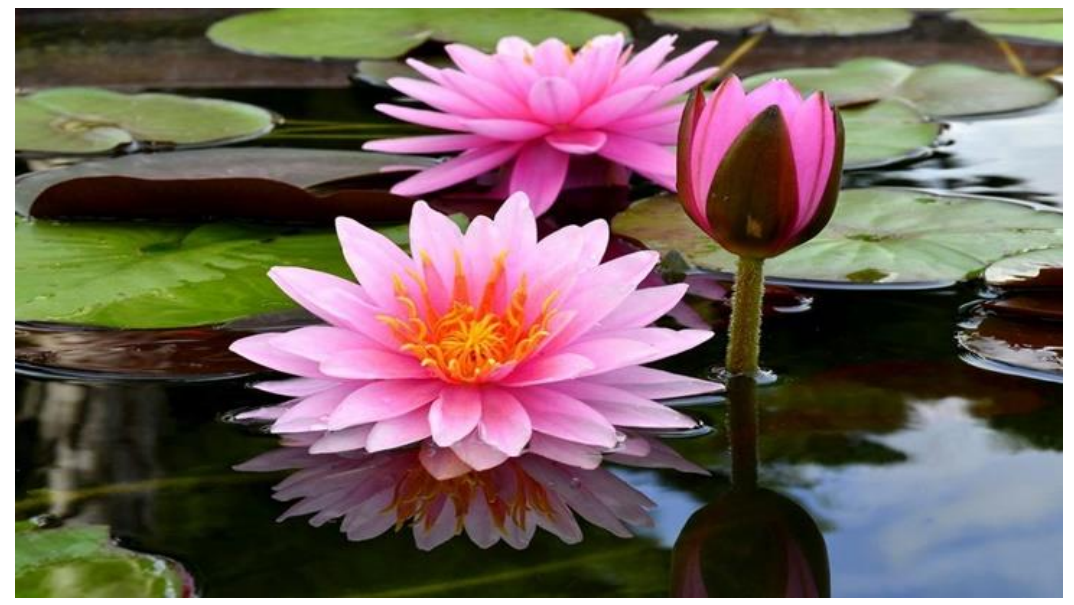

Gambar 14. Bunga Teratai

Sumber : www.rumah.com 
Secara eksternal berupa dalam aspek ekonomi seperti tersedianya lapangan kerja berupa penjaga loket, adanya kios untuk berjualan, adanya uoah bagi masyarakat dalam pelestarian tumbuhan di kawasan.

- Umpan balik yang dirasakan tentang perilaku ekologis

Umpan balik bagi masyarakat berupa dengan adanya lingkungan yang baik dan dipenuhi tumbuhan dapat memberikan rasa nyaman bagi masyarakat sekitar.

- Pengetahuan

Adanya ruang interaktif sebagai program utama dalam perancangan kali ini memberikan wawasan, pengetahuan, serta pengalaman baru bagi masyarakat perkotaan tentang pentingnya kesadaran terhadap lingkungan.

\section{PROGRAM}

Program yanng didapat dari hasil analisis kawasan, sebagai berikut :

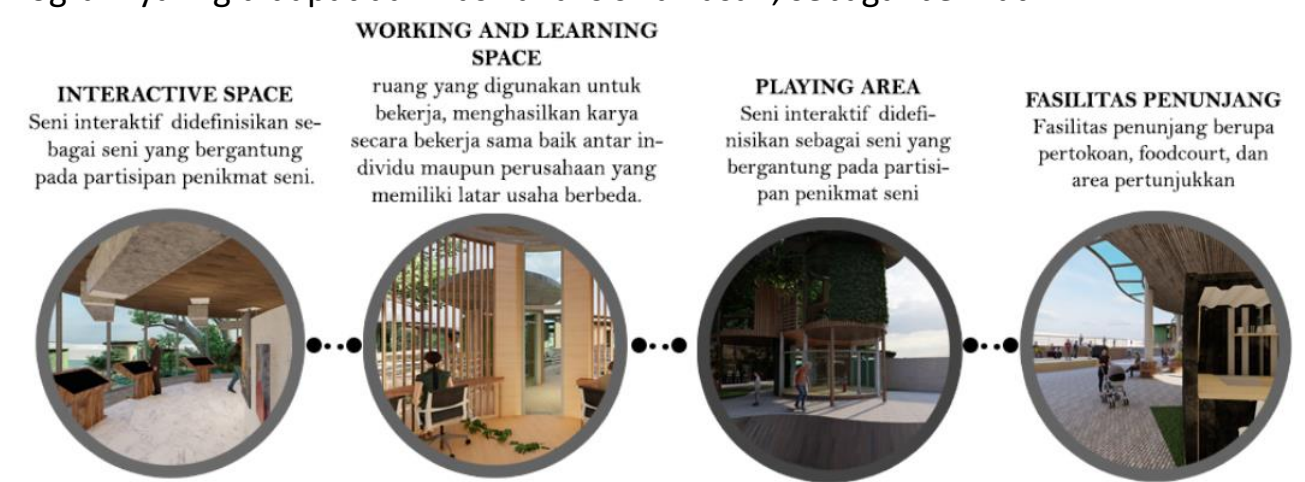

Gambar 15 .Program

Sumber : Penulis,2021

Dari issue yang diambil dibutuhkan bentuk bangunan dengan pendekatan dengan alam sehingga bentuk rancangan juga mengacu pada desain "Biofilik Arsitektur". Bentuk massa bangunan menggunakan biomorfik dari tanaman teratai dengan pola-pola yang diambil dari kehidupan teratai sebagai berikut:
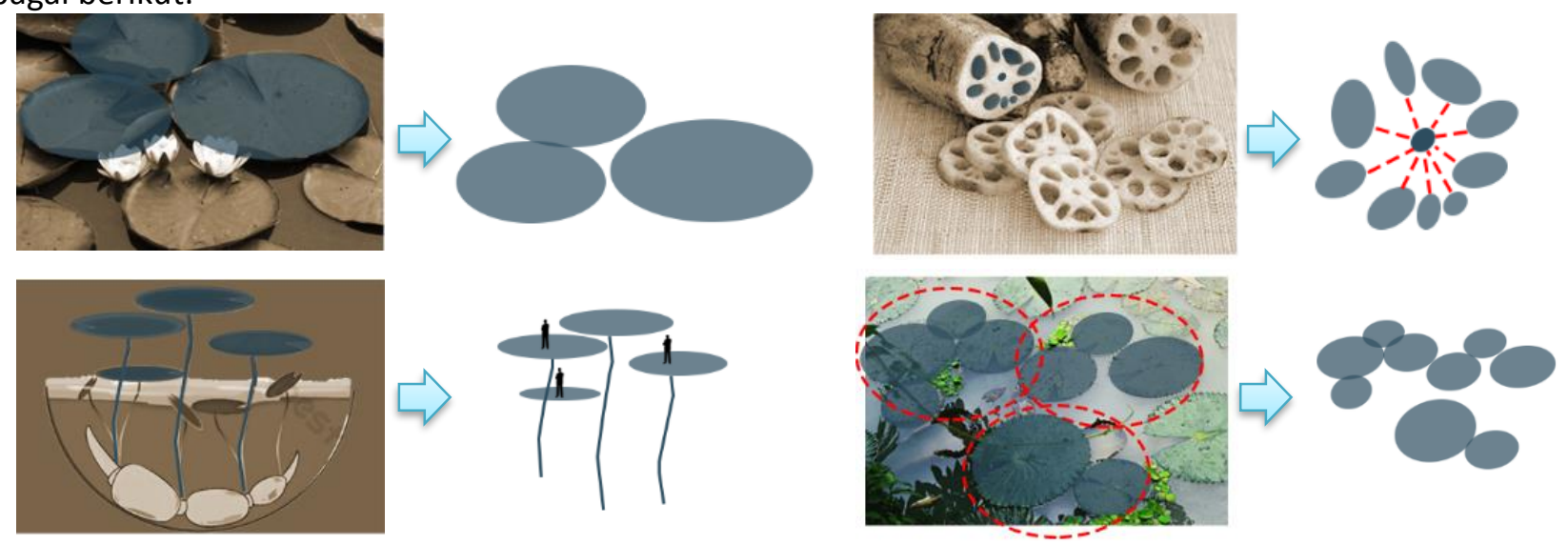

Gambar 16.Pola pola Tumbuhan Teratai

Sumber : penulis, 2021

Dari bentuk pola bunga teratai diatas disatukan dengan jalur sirkulasi, zoning, program, analisis tapak, dan kawasan. 


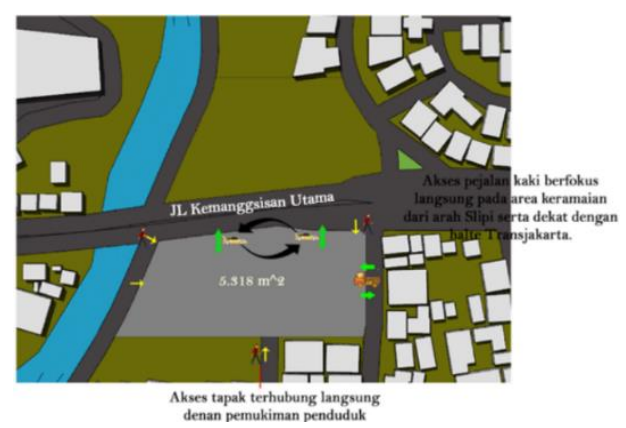

Gambar 17 Perancangan Akses Tapak

Sumber : penulis, 2021

Akses masuk tapak berada di setiap sisi dari tapak dengan bagian depan (JL Kemanggisan Utama) sebagai jalan utama merupakan akses masuk utama . Jalur pedestrian berada di bagian kanan dan kiri tapak sehingga langsung terhubung dengan jalur pejalan kaki dan dekat dengan halte transjakarta. Selain itu, jalur pejalan kaki juga masuk dari bagian jalur belakang yang merupakan pemukiman warga. Area parkir berada di sisi depan (JL Kemanggisan Utama) dan sisi kanan tapak yang merupakan jalan lokal Kemanggisan sebagai area parkir pengelola dan loading dock. Ruang interaktif berbasis ekologis terdisi dari 4 lantai ( 1 semi basement +3 lantai), antara lain :

Lantai Semi Basement : food court, toko retail, kantor privat, area bermain, dan ruang publik.

Lantai Dasar $\quad$ : ruang interaktif, raung bekerja dan belajar, pintu masuk utama.

Lantai $1 \quad$ : ruang interaktif dan area peristirahatan.

Lantai $2 \quad$ : kantor penggelola dan mini audio visual.
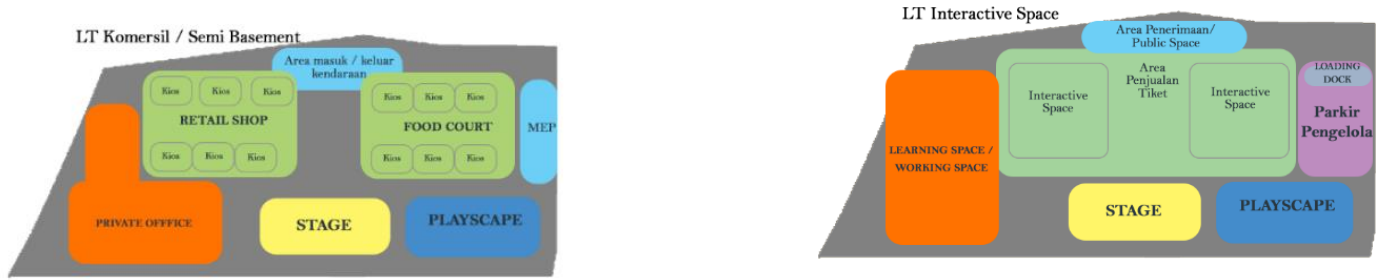

Gambar 18. Zoning Perancangan

Sumber : penulis,2021

Zoning perancangan disesuaikan dengan kondisi tapak dan lingkungannya, dibagi menjadi beberapa zona yaitu bagian ruang bekerja dan belajar berada di bagian kiri tapak dekat dengan anak sungai agar memberikan view yang baik serta tidak langsung berbatasan dengan jalan utama untuk menghindari kebisingan. Bagian area bermain (playscape) terletak di bagian pojok kanan belakang tapak agar memiliki proteksi ruang main yang lebih optimal terhadap anak anak. Adapun, area komersil beserta panggung pertunjukan berada di bagian tengah sebagai pusat keramaian dan rekreasi pengunjung. Selain itu, ruang seni interaktif yang merupakan program utama dari tapak dimaskudkan agar menjadi pusat perhatian dan vocal point dari proyek Ruang Interaktif Berbasis Ekologis ini. Di bagian depan tapak berupa kantor pengelola untuk memisahkan zona privat dan publik. 


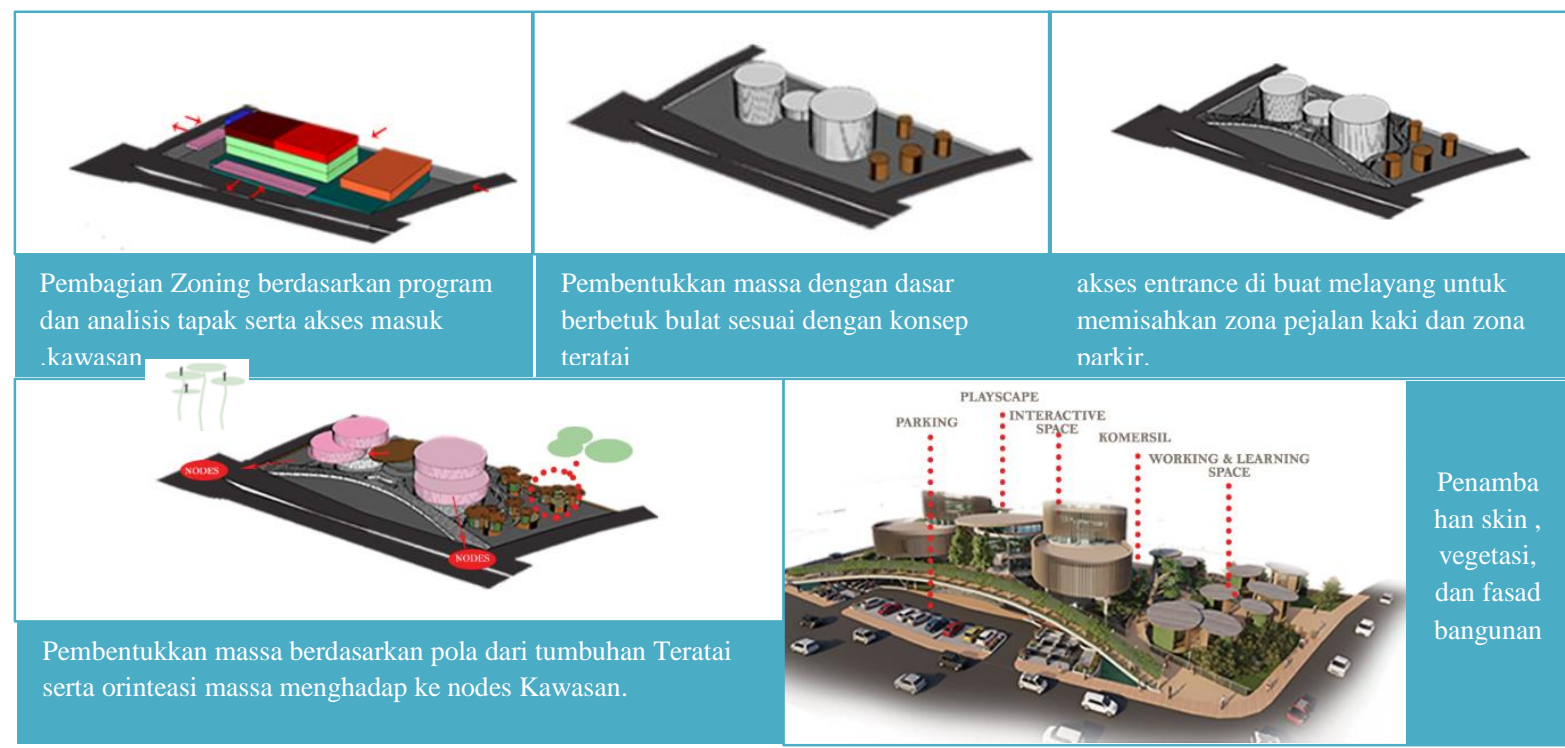

Gambar 20. Gubahan masa

Sumber : penulis, 2021

Jadilah sebuah gubahan yang mewadahi program ruang seni interaktif, ruang bekerja dan belajar, area bermain, dan fasilitas penunjang lainnya. Keseluruhan bangunannya merepresentasikan sebuah proyek yang cocok untuk kawasan Kemanggisan dengan program didalamnya yang mendukung tumbuhnya rasa pro-lingkungan bagi para penggunanya. Bentuk bangunannya pun tidak kaku dan monoton, melainkan terlihat bermain yang merepresentasikan sebuah proyek Beyond Ecology.

\section{KESIMPULAN DAN SARAN}

\section{Kesimpulan}

Didaerah Palmerah yang terletak di kawasan yang sangat strategis di tengah perkotaan dan memiliki tingkat kepadatan aktivitas yang tinggi sehingga menghilangkan empati masyarakat tentang lingkungannya. Melalui Ruang Interaktif Berbasis Ekologis ini dapat memberikan wadah bagi masyarakat bagi dari dalam maupun luar kota agar dapat mengarah ke perilaku ekologis dengan melibatkan keseharian dari masyarakat itu sendiri. Selain itu, dengan desain biofilik menjadi salah satu konsep desain yang mendukung dan membangun pemikiran pro-lingkungan bagi masyarakat. Dengan adanya Ruang Interaktif Berbasis Ekologis menjadi wadah aktivitas masyarakat yang memenuhi kaidah pro-lingkungan dan merubah cara pandang serta pola pikir masyarakat terhadap ekologi.

\section{Saran}

Perancangan dilaksanakan pada saat pademi COVID-19 sehingga perlunya studi lunjutan terutama studi lapangan untuk lebih mendalami mengenai kebiasaan dan kebutuhan masyarakat Palmerah agar proyek tepat sasaran. Penting juga melihat kondisi dan situasi site secara langsung agar dapat merasakan langsung suasana dan kondisi tapak serta sekitarnya yang tidak dapat dirasakan melalui analisis digital agar menjadikan proyek Interactive Art Space ini menjadi proyek yang beguna bagi masyarakat luas.

\section{REFERENSI}

Bratton, B. h. (2016). The Stack: On Software and Sovereignty. Cambridge: The MIT Press.

Browning, W., Ryan, C., \& Clancy, J. (2014). 14 Pattern Of Biophilic Design. New York: Terrapin Bright Green LLC.

Heriyanto, H. (2005). Majalah Tropika. In H. Heriyanto, Krisis Ekologi dan Spiritualitas Manusia (p.

21). Jakarta: Conservation International Indonesia. 
Kollmuss, A., \& Agyeman, J. (2002). Environmental Education Research, Vol. 8, No. 3. Mind the Gap: why do people act environmentally and what are the barriers to pro-eviromental Behavior?, 246-247.

Kurniawan, R. (2020, December 14). Kendaraan Bermotor Sumbang 60 Persen Polusi di Indonesia. Retrieved February 29, 2021, from Kompas.com: https://otomotif.kompas.com/read/2020/12/14/082200615/kendaraan-bermotor-sumbang60-persen-polusi-di-indonesia

Nasr, S. H. (2005). Antara Tuhan, Manusia, dan Alam. In S. H. Nasr, Jembatan Filosofis dan (p. 28). Yogyakarta: IRCiSoD.

Rastika, I. (2016, 5 20). Delapan Sungai di Jakarta Tercemar. Retrieved Februrary 29, 2021, from Kompas.com: https://megapolitan.kompas.com/read/2016/05/20/16410211/delapan.sungai.di.jakarta.terce mar.

Satmaidi, E. (2015, August 2). Jurnal Penelitian Hukum. Konsep Deep Ecology Dalam Pengaturan Hukum Lingkungan, 151.

Satmaidi, E. (2015, August 2). Jurnal Penelitian Hukum. Konsep Deep Ecology Dalam Pengaturan Hukum Lingkungan, 151-152.

Sutanto, A. (2021, Februari 4). Dromos Oikos: Notes On The Fifth Ecology. Jakarta Barat, DKI Jakarta, Indonesia. 
